kind and friendly, though he could be quite firm in relation to the people with whom he had to deal. He was gifted with a quick intelligence which enabled him to understand complex situations in a few moments, and he was endowed with a very refined, inimitable and typically French sense of humour.

His exceptional human qualities enabled him to keep on good terms with the majority of his senior colleagues and they made him popular among the staff of the Pasteur Institute. He appointed judiciously and, on the whole, successfully, new members of the staff and succeeded in maintaining the very high scientific standards of the Institute. He also created and maintained close contacts with the French pharmaceutical industry, to both its own benefit and that of the Pasteur Institute.

In my view, the Pasteur Institute never had a more dedicated and successful director than Jacques Tréfouël.

Throughout his onerous social duties as Director-General of the Pasteur Institute, Jacques Tréfouël received extensive, continuous and competent support from his wife who combined the properties of an excellent scientist with those of a perfect hostess. Time passed quickly during the animated and witty conversations covering a wide range of subjects at their elegant parties, which remained an unforgettable experience in the memory of those privileged to participate in them.

Jacques Tréfouël received numerous high honours from the French and other Governments and scientific societies. Among these were his nomination to the grade of a Grand Officer of the Legion d'Honneur, to the Membership and later Presidency of the French Academy of Sciences and the National Academy of Medical Sciences, many honorary degrees in the Universities of Europe, including Oxford and Cambridge in this country, and the Americas, and membership of many foreign academies and learned societies.

The passing of Jacques Tréfouël marks the end of an era in European science.

Ernst Chain

\section{G. K. Green}

George Kenneth Green, or Ken Green as he was known in the world of particle accelerators, died on 15 August 1977 of a heart attack while visiting his son at Brownsville, Texas. He was 66 years of age and had lived through, and taken a leading part in, one of the most extraordinary technological de- velopments of our time.

Ken Green was born in St David, Illinois, and retained all his life the looks and the dry humour of a MidWesterner. He went to Illinois University, obtained a Ph.D. degree in physics there in 1937, and stayed on a year afterwards as an Associate in Physics. His first experience with what became his life's work was at the Radiation Laboratory of the University of California where he did design work on cyclotrons and nuclear physics research. It was there, at what was then the fountainnead of accelerator developments, under the inspiration and leadership of Ernest Lawrence, that Ken Green must have fallen in love with accelerators. He also spent a short time at the Department of Terrestrial Magnetism of the Carnegie Institution of Washington D.C.

He spent the war years with the Army Signal Corps, joining in 1942 as a second lieutenant, and in 1946 he was Army Electronic Representative and Technical Head of the Signal Corps Group at Operation Crossroads at Bikini. Later, he became principal physicist at the Evans Signal Laboratory of the Signal Corps at Belmar, New Jersey. During this period he worked on sonar and was one of the inventors of the proximity fuse, an important advance in firing rockets and artillery. At the Bikini test of atomic bombs he was involved in the development of instrumentation to study nuclear explosions. For his services during the war he received both the Civilian Distinguished Service Award and the US Army Legion of Merit.

Ken Green joined the Brookhaven National Laboratory in 1947 to work on the 'Cosmotron' and he never left that laboratory nor accelerator building for the rest of his life. The Cosmotron, in its time, was the largest accelerator in the world, and with a top energy of $3 \mathrm{GeV}$ it was the first accelerator to exceed one thousand million electron volt particle energy. Ken Green was involved in the design and construction of every part of this machine. Formally, he was a senior scientist; in practice he combined a considerable design ability across the whole field of accelerator technology with a remarkable talent for supervising the construction of this giant machine-a talent rather rare in those days. The result was that Ken Green knew every detail of the Cosmotron, the reasoning behind its design, how it was constructed, and how well or badly it operated. No wonder that he earned the name of 'Mr. Cosmotron.'

The construction of the Cosmotron was finished in 1952, and many im- provements were made to it subsequently, in all of which Ken Green was intimately involved. Meanwhile, another, even bigger accelerator project was being quietly conceived at Brookhaven, and in Europe a new international laboratory was being set up, called CERN, which aimed at building a similar machine. Then followed one of those unofficial and extremely effective collaborations between two laboratories which prove so beneficial to the course of scientific research, and Ken Green entered whole-heartedly into this collaboration.

The two machines, the $30 \mathrm{GeV}$ AGS at Brookhaven and the $25 \mathrm{GeV}$ CPS at CERN were essentially designed together. The principle of alternating gradient focusing was discovered at Brookhaven at this time, and the two teams worked out the consequences of this important idea together, and based the design of their machines on this new principle. Brookhaven staff came to Europe, CERN staff went to Brookhaven, and the success of these two machines owed much to the close collaboration between Ken Green's team at Brookhaven and the CERN team at Geneva.

The two machines came into operation at about the same time in 1960 , and the two teams celebrated each other's success. The AGS and CPS were for many years the highest energy accelerators in the world. Ken Green became the Chairman of the Accelerator Department of the Brookhaven National Laboratory in 1960, having first served for a while as deputy-chairman under Leyland Haworth, and he held that post until 1970.

His last most notable contribution to accelerator design was the electron machine for the National Synchrotron Light Source which he started before his official retirement from Brookhaven Laboratory and continued for the short while afterwards until his death. Construction of this machine is due to start at Brookhaven towards the end of 1977. His last appearance in Europe was in the spring of this year when he came over to CERN to participate in the inauguration of the European $400 \mathrm{GeV}$ SPS machine.

Ken Green has earned an immortal place in the ranks of the great accelerator builders with the Cosmotron and the AGS which were not only the highest energy machines of their time but also very challenging projects, involving many technological advances. All his many friends and colleagues throughout the world, in all the laboratories where these giant machines exist, will mourn his death, and remember with gratitude the help and encouragement he has given them.

J. B. Adams 